\title{
HAUPT, Barbara, BUSSE, Wilhelm G., Pilgerreisen in Mittelalter und Renaissance
}

\section{Denise Péricard-Méa}

\section{OpenEdition}

\section{Journals}

Édition électronique

URL : http://journals.openedition.org/ifha/517

DOI : $10.4000 /$ ifha. 517

ISSN : 2198-8943

\section{Éditeur}

IFRA - Institut franco-allemand (sciences historiques et sociales)

\section{Référence électronique}

Denise Péricard-Méa, «HAUPT, Barbara, BUSSE, Wilhelm G., Pilgerreisen in Mittelalter und Renaissance », Revue de l'IFHA [En ligne], Date de recension, mis en ligne le 01 janvier 2007, consulté le 22 septembre 2020. URL : http://journals.openedition.org/ifha/517 ; DOI : https://doi.org/10.4000/ifha. 517

Ce document a été généré automatiquement le 22 septembre 2020.

(C)IFHA 


\title{
HAUPT, Barbara, BUSSE, Wilhelm G., Pilgerreisen in Mittelalter und Renaissance
}

\author{
Denise Péricard-Méa
}

Sous le titre Pèlerins au Moyen Age et à la Renaissance, les éditions Droste ont publié en 2006, dans la collection Studia Humanoria, un recueil de conférences prononcées à l'Institut de recherche sur le Moyen Âge et la Renaissance de l'université HeinrichHeine à Düsseldorf pendant l'hiver 1997-98. Cette publication a été faite à la mémoire du professeur Anne-Marie Schimmel (décédée en janvier 2003). D'Anne-Marie Schimmel elle-même, cet ouvrage publie l'article « Pèlerinage - un voyage au centre de l'Islam » à partir de notes qu'elle avait revues et corrigées.

Outre l'article précité, les conférences reproduites sont les suivantes (les titres sont traduits) : « “Je suis venu, j'ai vu et j'ai touché ". Jérusalem, un but de pèlerinage à la fin du Moyen Âge », par U. GANZ-BLÄTTER - «Pregrinatio et stabilitas » dans le monde monastique au début du Moyen Âge, par J. SEMMLER - « Du pèlerinage en armes au voyage de découverte ", l'art poétique moyen-haut allemand de Herzog Ernst », par B. HAUPT - « Le récit de voyage de Arnold von Harff », par H. KOKOTT - « Pèlerinages vers Canterbury », par W. G. BUSSE - " Neuss et Düsseldorf, buts de pèlerinage au Moyen Âge ", par H. FINGER - " Piété et politique ", pèlerins dans la Pologne catholique et la Russie orthodoxe, par H. HECKER - « La chemise de la Justice », pèlerins et touristes au tombeau du pape Paul III à Saint-Pierre de Rome, par H. KÖRNER - « Régimes médicaux pour les pèlerinages ", par H. SCHADEWALDT.

Curieusement, mais c'est un avantage, cet ouvrage de chercheurs allemands n'aborde qu'indirectement le thème du pèlerinage de Compostelle devenu une banalité depuis que les politiques s'en sont emparés en faisant des Chemins de Compostelle un Itinéraire Culturel Européen. Il ne se limite pas non plus aux pèlerinages chrétiens. A.M. SCHIMMEL fait découvrir la profonde transformation que peut apporter au pèlerin musulman la rencontre avec la «fiancée » de la Mecque, la mystérieuse Kaaba, symbole 
d'une rencontre tout autre. Elle rappelle que tous les pèlerins ont pour Ancêtre Abraham qui s'est mis en route à l'appel de son Dieu.

Outre les grands pèlerinages de Jérusalem et Rome, l'ouvrage a le grand avantage, surtout pour le lecteur francophone, de faire découvrir des pèlerinages locaux ou régionaux dont on parle trop peu. Qui connaît l'histoire du crâne de saint Quirien à Neuss? L'approche parfois anecdotique des grands pèlerinages permet de sortir des sentiers battus et fait l'intérêt de cet ouvrage malgré le temps assez long qui sépare sa publication de la date des conférences.

Plusieurs d'entre elles sont complétées d'importantes notes qui permettront aux chercheurs d'approfondir les sujets traités. L'article de J. SEMMLER est à cet égard particulièrement riche. Son thème très général fait remonter aux origines de l'évangélisation de l'Europe. La plupart des articles montrent bien que le pèlerinage est une entreprise multiforme qui ne peut être limitée à son aspect religieux. Politique et tourisme y sont étroitement mêlés. Le lecteur français apprendra ainsi avec surprise et intérêt, que sur le chemin du retour de Compostelle, Arnold von Harff a (aurait ?) rencontré Louis XII à la messe à la Sainte-Chapelle. Dernier article de l'ouvrage, la contribution consacrée aux pratiques médicales mérite également d'être signalée car le thème n'est pas abordé fréquemment.

Il faut donc savoir gré aux éditeurs d'avoir rassemblé ces textes et de les avoir mis à la disposition du public et des chercheurs qui poursuivront la pérégrination dans les pas de leurs prédécesseurs.

Denise PERICARD-MEA (Fondation David Parou Saint-Jacques/ Laboratoire de Médiévistique Occidentale de Paris) 